\title{
Cerebellum: links between development, developmental disorders and motor learning
}

\author{
Mario U. Manto ${ }^{1 *}$ and Patrice Jissendi ${ }^{2}$ \\ ${ }^{1}$ FNRS, Neurologie, Unité d'Etude du Mouvement, Hôpital Erasme-ULB, Bruxelles, Belgium \\ 2 Service de Neuroradiologie, Hôpital Erasme-ULB, Bruxelles, Belgium
}

\author{
Edited by: \\ José A. Armengol, University Pablo \\ de Olavide, Spain \\ Reviewed by: \\ José A. Armengol, University Pablo \\ de Olavide, Spain \\ José M. Delgado-García, University \\ Pablo de Olavide, Spain \\ *Correspondence: \\ Mario U. Manto, FNRS, Neurologie, \\ Unité d'Etude du Mouvement, \\ Hôpital Erasme-ULB, 808 Route de \\ Lennik, 1070 Bruxelles, Belgium. \\ e-mail:mmanto@ulb.ac.be
}

The study of the links and interactions between development and motor learning has noticeable implications for the understanding and management of neurodevelopmental disorders. This is particularly relevant for the cerebellum which is critical for sensorimotor learning. The olivocerebellar pathway is a key pathway contributing to learning of motor skills. Its developmental maturation and remodeling are being unraveled. Advances in genetics have led to major improvements in our appraisal of the genes involved in cerebellar development, especially studies in mutant mice. Cerebellar neurogenesis is compartmentalized in relationship with neurotransmitter fate. The Engrailed-2 gene is a major actor of the specification of cerebellar cell types and late embryogenic morphogenesis. Math1, expressed by the rhombic lip, is required for the genesis of glutamatergic neurons. Mutants deficient for the transcription factor Ptf1a display a lack of Purkinje cells and gabaergic interneurons. Rora gene contributes to the developmental signaling between granule cells and Purkinje neurons. The expression profile of sonic hedgehog in postnatal stages determines the final size/shape of the cerebellum. Genes affecting the development impact upon the physiological properties of the cerebellar circuits. For instance, receptors are developmentally regulated and their action interferes directly with developmental processes. Another field of research which is expanding relates to very preterm neonates. They are at risk for cerebellar lesions, which may themselves impair the developmental events. Very preterm neonates often show sensori-motor deficits, highlighting another major link between impaired developments and learning deficiencies. Pathways playing a critical role in cerebellar development are likely to become therapeutical targets for several neurodevelopmental disorders.

Keywords: cerebellum, learning, developmental, inferior olive, Purkinje neurons, genes, transcription factors

\section{INTRODUCTION}

Cerebellum plays critical roles in learning sensorimotor tasks (Manto, 2010). For instance, it is widely accepted that the olivocerebellar tract in one of the key pathways contributing to learning of new motor skills (Ito, 2006). However, although the involvement of cerebellar circuits in motor learning is known to be critical, their precise role in the acquisition and storage of new motor abilities or rather in the performance of the acquired motor skills is still a matter of debate. Several authors have pointed that attention should be paid to functional states (as opposed to neural sites) able to generate motor learning in mammals (Delgado-García and Gruart, 2002). Permanent or temporary disconnection of a given nodal center in a neural circuit will not determine the whole functional state of the involved circuit and the transformation of neural signals occurring at the different neural centers included in the circuit (Harvey et al., 1993; Delgado-García and Gruart, 2002).

There is currently a growing awareness that neurodevelopmental disorders are associated with cerebellar deficits and learning impairments. Still, the molecular mechanisms of the cerebellar defects remain poorly understood in many cases. Cerebellum is likely to become a major platform to investigate how development and learning interact in mammals. Indeed, cerebellar circuits are modular and stereotyped from the morphological standpoint and provide thus a structure of choice to investigate the relationships between regional developmental defects and learning, especially from the anatomical/functional point of view. Moreover, marked morphological changes still occur after birth, allowing the detailed assessment of developmental abnormalities with various techniques and their phenotypical impact after the pregnancy. In addition, developmental studies have revealed that the cerebellum evolves in successive waves of progenitors proliferation/migration throughout the embryonic and postnatal phases. The possibility to act selectively on these waves opens new therapeutic doors.

This review covers recent advances in the understanding of the gene networks contributing to cerebellar development, discusses the impact of very premature birth upon cerebellar development and underlines the critical steps of the development of the olivocerebellar tract. Potentially clinically relevant discoveries are highlighted.

\section{THE KEY-FEATURES OF CEREBELLAR DEVELOPMENT}

Because the circuits of the cerebellum are unique in their morphology, the mechanisms of cerebellar neurogenesis are a subject 
of intense investigation (Carletti and Rossi, 2008). Neuronal/glial migrations as well as dendritogenesis are fundamental processes leading to functional cerebellar microcircuits being effective for plasticity and learning. Interestingly, the anatomy of the cerebellum with a midline vermis and two hemispheres located laterally is highly conserved from rodents to human, suggesting that the analysis of the development in rodents should provide direct relevant informations in human, including for cerebellar malformations.

The major features of cerebellar development can be briefly summarized as follows. Neuronal populations are generated in a sequential manner. The inhibitory interneurons emerge from the ventricular zone and the glutamatergic neurons are generated by the rhombic lip (Carletti and Rossi, 2008). In mouse, the glutamatergic and gabaergic neurons in nuclei are produced first, followed by Purkinje neurons. It is established that gabaergic interneurons of the cerebellar cortex originate from a ventricular zone progenitor (Leto and Rossi, 2011). After generation of cerebellar nuclei, the external granular layer is formed from precursors of granule cells originating from the rhombic lip. Granule cells will migrate to form the internal granular layer. It is interesting to note that these events occur at the third trimester of development in human (see also below the impact of very premature birth upon cerebellar development). Survival and maintenance of Purkine neurons and granule cells is dependent on the antiapoptotic protein Lifeguard, which is highly expressed in the cerebellum and is strongly upregulated during postnatal brain development (Hurtado de Mendoza et al., 2011). Lifeguard antagonizes the FAS pathway. FAS receptors tune neuronal survival following trophic factors deprivation (Raoul et al., 2000). Lifeguard affects cerebellar size, internal granular layer thickness, and Purkinje cell development, suggesting that lifeguard could participate in the pathogenesis of various human cerebellar disorders characterized by cerebellar atrophy. Glutamatergic unipolar brush cells migrate to the internal granular layer. Whereas the ventricular zone will lose its progenitors at late embryogenic stages, the rhombic lip remains active until postnatal period.

\section{CEREBELLUM, HORMONES, AND NEUROSTEROIDOGENESIS}

The relationship between circulating hormones and cerebellar development is well demonstrated. In particular, thyroid hormone plays a critical role in brain development (Koibuchi, 2008). The thyroid hormone receptor is a ligand-regulated transcription factor binding to a specific DNA sequence called thyroid-hormone-responsive element. The receptor recruits various coregulators such as coactivator and corepressor in a liganddependent manner to modulate the transcription of target genes (Koibuchi, 2008). It may also interact with other nuclear receptors such as Rora (retinoic-acid-related orphan receptor alpha; see below) whose expression is regulated by the thyroid hormone during the first postnatal two weeks.

In perinatal hypothyroidism, the growth and branching of Purkinje cell dendrites are greatly reduced, there is a reduction of synapses between granule cells and Purkinje neurons, migration of granule cells to the internal granule cell layer is delayed and synaptic connectivity within the cerebellar cortex is deficient (Nicholson and Altman, 1972; Koibuchi et al., 2003, 2008; Figure 1). Thyroid deficient rats show a persistence of synaptic sites of climbing fibers for a longer time (see section on the remodeling of the olivocerebellar projection) along with an underdevelopment of cerebellar glomeruli (Hajós et al., 1973). Performance of the hypothyroid animals is impaired in tests of adaptive behavior.

The discovery that Purkinje neurons possess steroidogenic enzymes and produce progesterone from cholesterol in the neonatal period has provided a link between steroidogenesis and development of cerebellar circuits (Sakamoto et al., 2001). Concentrations of progesterone and allopregnenolone are high in the cerebellum during the post-natal life (Tsutsui, 2008). The group of Tsutsui has demonstrated that progesterone promotes dendritic growth and spine formation in Purkinje neurons (Sakamoto et al., 2001). Neurosteroids have a direct effect upon synaptogenesis during the neonatal development. Formation of cerebellar circuitry is dependent on a local steroidogenesis, acting through neurotrophic factors such as BDNF (Sasahara et al., 2007). This emphasizes a potential novel bridge between neurosteroidogenesis and motor learning, with possible therapeutical implications in developmental disorders.

\section{THE ENGRAILED-2 GENE}

The engrailed (En) homeobox transcription factor family is critical for the patterning of cerebellar lobules and for Purkinje cells protein stripes (Kuemerle et al., 1997). The En1/2 regulates the targeting of mossy fiber systems to subsets of cerebellar lobules, showing a main role for the afferent topography in the cerebellar circuitry (Sillitoe et al., 2010). Initially, the En $1 / 2 \mathrm{mRNA} /$ protein are expressed in the ventricular zone. During early post-natal cerebellogenesis, En1/2 are expressed in spatially restricted patterns in most cell types. It is plausible that En $1 / 2$ are implicated in neurodevelopmental disorders such as autism spectrum disorder (see also below). Indeed, mutant mice EN2-/- show neurobehavioral and neurochemical deficits suggestive of autism spectrum disorder (Cheh et al., 2006).

\section{MATH1}

The specification and differentiation of glutamatergic lineages is dependent upon Math1, a transcription factor of the bHLH class. Math1 is critical for the proper development of the granular layer of the cerebellum. Mice deficient in Math1 show a loss of glutamatergic neurons in cerebellar nuclei, a loss of external granular layer and unipolar brush cells. In addition, Math1 null embryos lack interneurons giving rise to the spinocerebellar and cuneocerebellar tracts (Bermingham et al., 2001).

\section{PTF1A AND ASCL1}

Cerebelless mutants have a deficit in the transcription factor Ptfla (pancreatic transcription factor 1a). They show a lack of Purkinje cells and gabaergic interneurons. It has been demonstrated that climbing fiber neurons are derived from the Ptfla domain (Yamada et al., 2007). In Ptfla null mutants, immature climbing fiber neurons cannot migrate or differentiate, causing a failure in the formation of the inferior olivary nucleus. Ptfla is also involved in the control of fate and survival of neurons during 


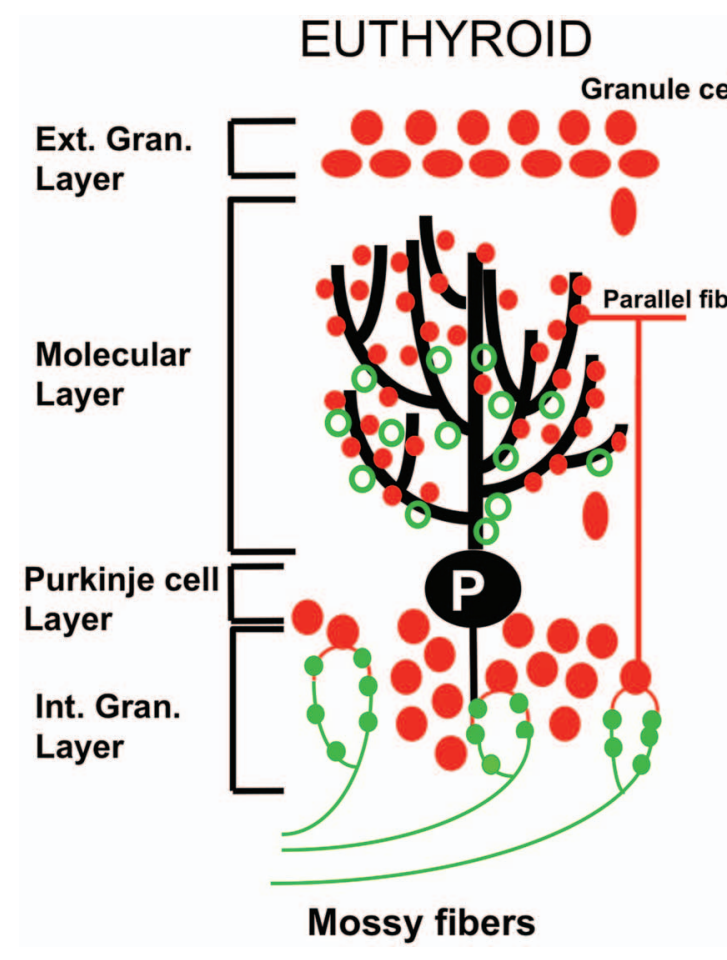

FIGURE 1 | Effect of perinatal hypothyroidism on neurogenesis and differentiation of the cerebellar cortex. In the hypothyroid cerebellum (right panel), disappearance of the external granular layer is delayed consequently to the retarded proliferation and migration of granule cells to the internal granular cell layer. The arborisation of the dendrites of Purkinje neurons $(P)$ is

development. In human, mutations of Ptfla are associated with cerebellar agenesis (Sellick et al., 2004).

Ascl1 directs ventricular neuroepithelium progenitors toward inhibitory interneuron fate and suppresses the astrocytic differentiation (Grimaldi et al., 2009). Mice lacking Ascl1 in the cerebellum exhibit a major decrease of cerebellar interneurons and an imbalance between oligodendrocytes and astrocytes (Sudarov et al., 2011).

\section{RORA (RETINOIC-ACID-RELATED ORPHAN RECEPTOR ALPHA) GENE}

Rora is a transcription factor encoding a retinoid-like nuclear receptor which is highly expressed in the cerebellum (Hamilton et al., 1996). Rora belongs to the steroid-thyroid hormone receptor superfamily (Koibuchi, 2008). Its endogenous ligand is cholesterol which is abundantly present in each cell. Therefore, Rora acts as if it is a constitutively active nuclear receptor (Koibuchi, 2008). It was initially thought that Rora was exclusively expressed in neurons, but recent data show that it is also expressed in glial cells especially in astrocytes (Journiac et al., 2009). Rora plays a pivotal role in the development of the cerebellum, olfactory bulb, and retina (Jetten, 2009). However, its functions extend beyond development. For instance, Rora also protects neurons against oxidative stress and shows an anti-inflammatory action by inhibiting the NF-Kappa-B pathway (Delerive et al., 2001; Boukhtouche et al., 2006).

\section{HYPOTHYROID Granule cell}

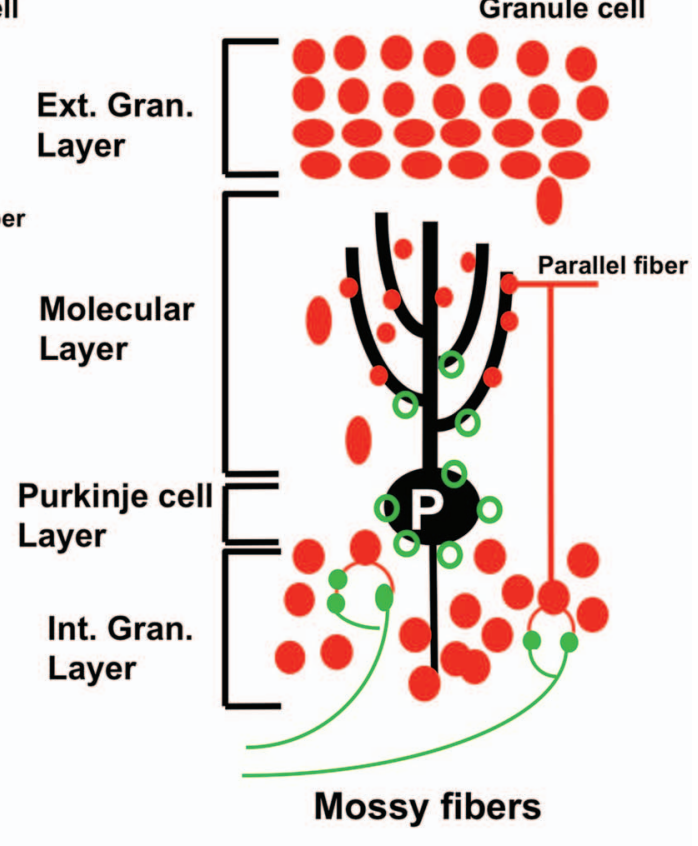

decreased. The connectivity between parallel fibers (pf; red closed circles) and Purkinje cells is reduced. The synaptic connections between mossy fibers (mf; green closed circles) and granule cells are decreased as compared to the euthyroid condition. Green open circles: climbing fibers synapses. Adapted from Koibuchi et al. (2003).

The autosomal recessive staggerer mutation is associated with a severe degeneration of Purkinje neurons with a nearly total absence of granule cells at the end of the first postnatal month (Landis and Sidman, 1978). The homozygous mouse Rora $^{\text {sg }} /$ Rara $^{\text {sg }}$ is highly ataxic, whereas the heterozygous mouse Rora $^{+} / \operatorname{Rara}^{\mathrm{sg}}$ appears phenotypically normal, showing disabilities during challenging tasks.

\section{REELIN AND CEREBELLAR DEVELOPMENT}

The external granular layer promotes Purkinje cell migration by secreting reelin (RELN), an extracellular matrix component attracting or repealing precursors and axons during development, acting as an extracellular signaling molecule. Reelin deficient mice (Reeler) show a severe cerebellar hypoplasia. They exhibit Purkinje cell migration defects and cerebellar nuclei are impaired. Foliation is absent. Reelin continues exerting activities beyond birth. It modulates long-term potentiation and is thus involved in learning (Beffert et al., 2004). In the adult brain, Reelin regulates structural and functional properties of synapses. Its overexpression may increase markedly the longterm potentiation responses and it has been proposed that Reelin controls developmental processes remaining active in the adult brain (Pujadas et al., 2010). In human, reelin might be implicated in some forms of lissencephaly (due to neuronal migration defect) and could contribute to the pathogenesis of autism (Figure 2). 

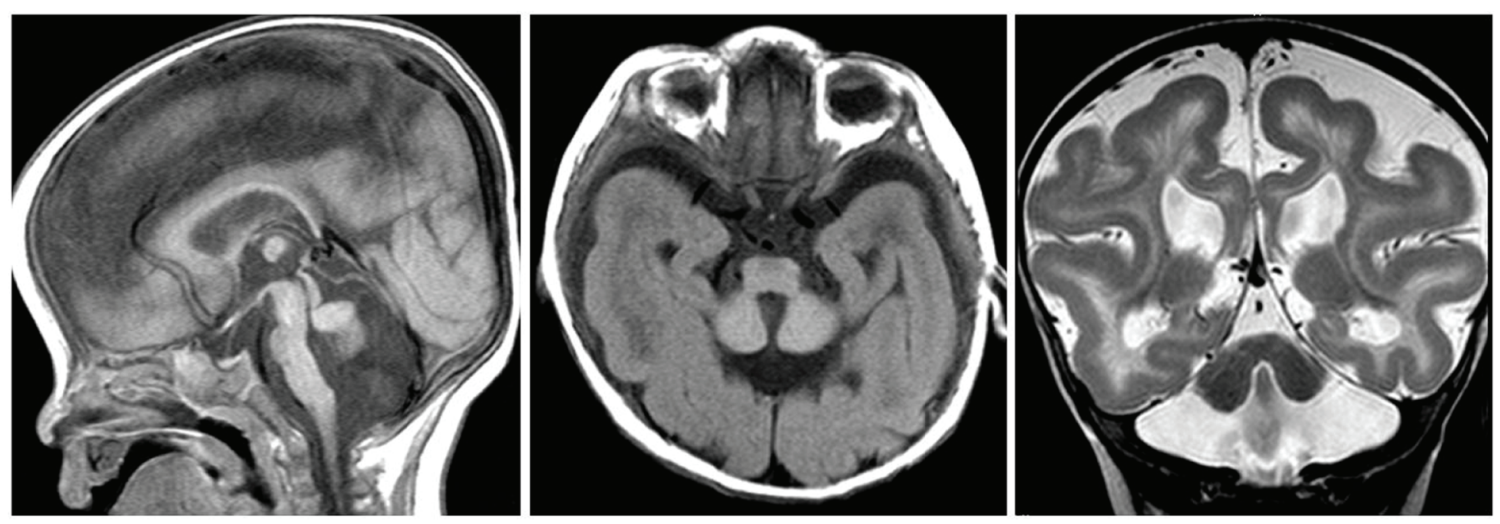

FIGURE 2 | RELN mutation. Sagittal (left panel) and axial T1- (middle panel), and coronal T2-weighted (right panel) images showing a very small afoliar vermis and cerebellar hemispheres. The severe hypoplasia of the cerebellum is associated with lissencephaly, cerebral hemispheres showing thickened cortex and simplified gyral pattern. Hippocampal hypoplasia and malrotation are part of the specific MRI features.

\section{THE CHEMOKINE RECEPTOR 4 (CXCR4)-CHEMOKINE LIGAND 12 (CXCL12) SYSTEM}

Chemokines and their receptors are determinant in cell migration and in organogenesis (Zou et al., 1998). CRXC4 and CXL12 mutant mice show proliferating granule cell progenitors located in deeper location (Zou et al., 1998). Down-regulation of CXCR4 causes an inward radial migration of granule cells precursors. The chemoattractant SDF- $1 \alpha$ and its receptor CXCR4 attract the cerebellar granular neuronal precursors to the outer external granular layer and promote an increase of the sonic hedgehog mitogenic effect (see next section).

\section{SONIC HEDGEHOG AND CEREBELLAR DEVELOPMENT}

Sonic hedgehog is highly expressed in the cerebellum (Vaillant and Monard, 2009). Sonic hedgehog is a morphogenetic factor which is a masterplayer in cerebellar patterning and foliation (Vaillant and Monard, 2009). Indeed, sonic hedgehog controls the proliferation of progenitors in the cerebellum (Figure 3). Sonic hedgehog pathway involves the GLI family of transcription factors. The binding of sonic hedgehog to the transmembrane receptor Patched 1 triggers a cascade of events tuning cAMP production (DeCamp et al., 2000). A link between cholesterol metabolism, sonic hedgehog and cerebellar development has been established. Indeed, cholesterol deficiencies are associated with defects in the sonic hedgehog signaling (cholesterol is an activator of sonic hedgehog) and cause cerebellar malformations (Lanoue et al., 1997). Hypoplasia of the cerebellum is classically associated with the Smith-Lemli-Opitz syndrome, an autosomal recessive syndrome with multiple congenital malformations, which is due to defects in cholesterol homeostasis (Dehart et al., 1997). Sonic hedgehog exerts critical mitogenic functions (Vaillant and Monard, 2009). For instance, sonic hedgehog stimulates very strongly the proliferation of cerebellar granular neuronal precursors through the induction and repression of cell cycle regulators genes (Wechsler-Reya and Scott, 1999). Blocking GLI2 causes a failure in the development of cerebellar granular neuronal precursors, ending in cerebellar hypoplasia (Corrales et al., 2004). In addition, sonic hedgehog contributes to cerebellar cortex development by promoting Bergmann glia proliferation and thus contributing to the migration support (Corrales et al., 2006; Vaillant and Monard, 2009). While delection of sonic hedgehog leads to an absence of foliation and underdevelopment of the cerebellum, the sonic hedgehog mutants show a larger cerebellum, even with an extralobule, demonstrating how sonic hedgehog determines cerebellar morphology and shape (Corrales et al., 2006). Cyclins D1 and D2 are transcriptional targets of sonic hedgehog. Delection of cyclin D2 is associated with a mild hypoplastic cerebellum (Huard et al., 1999).

The extra-cellular matrix undergoes a substantial remodeling during cerebellar development, providing cues for division or differentiation according to its content (Vaillant et al., 1999; Vaillant and Monard, 2009). Laminin and heparan sulfate proteoglycans increase the mitogenic effects of sonic hedgehog (Rubin et al., 2002).

Sonic hedgehog pathway is also controlled by negative regulators, such as PACAP (pituitary adenylate-cyclase activating polypeptide). Knock-out mice for PACAP show an overactive sonic hedgehog pathway with enlargement of the external granular layer (Nicot et al., 2002). Sonic hedgehog is also deactivated by FGF-2, which triggers the differentiation of neural precursors of granule cells (Fogarty et al., 2007).

Sonic hedgehog is implicated in the formation of medulloblastoma, an aggressive tumor of the cerebellum. Mutations of the PTC receptor lead to an overactivation of sonic hedgehog (Vaillant and Monard, 2009). The overexpression of sonic hedgehog in neural progenitors of the cerebellum causes a medulloblastoma (Weiner et al., 2002). GLI1 expression is markedly increased in a subgroup of patients developing a medulloblastoma (Ferretti et al., 2008). Development of sonic hedgehog antagonists might be considered to manage this tumor.

\section{THE pcd MODEL}

Purkinje cell degeneration ( $\mathrm{pcd}$ ), an autosomal recessive mutation in the mouse, causes the postnatal death of nearly all cerebellar Purkinje cells during the third and fourth postnatal 


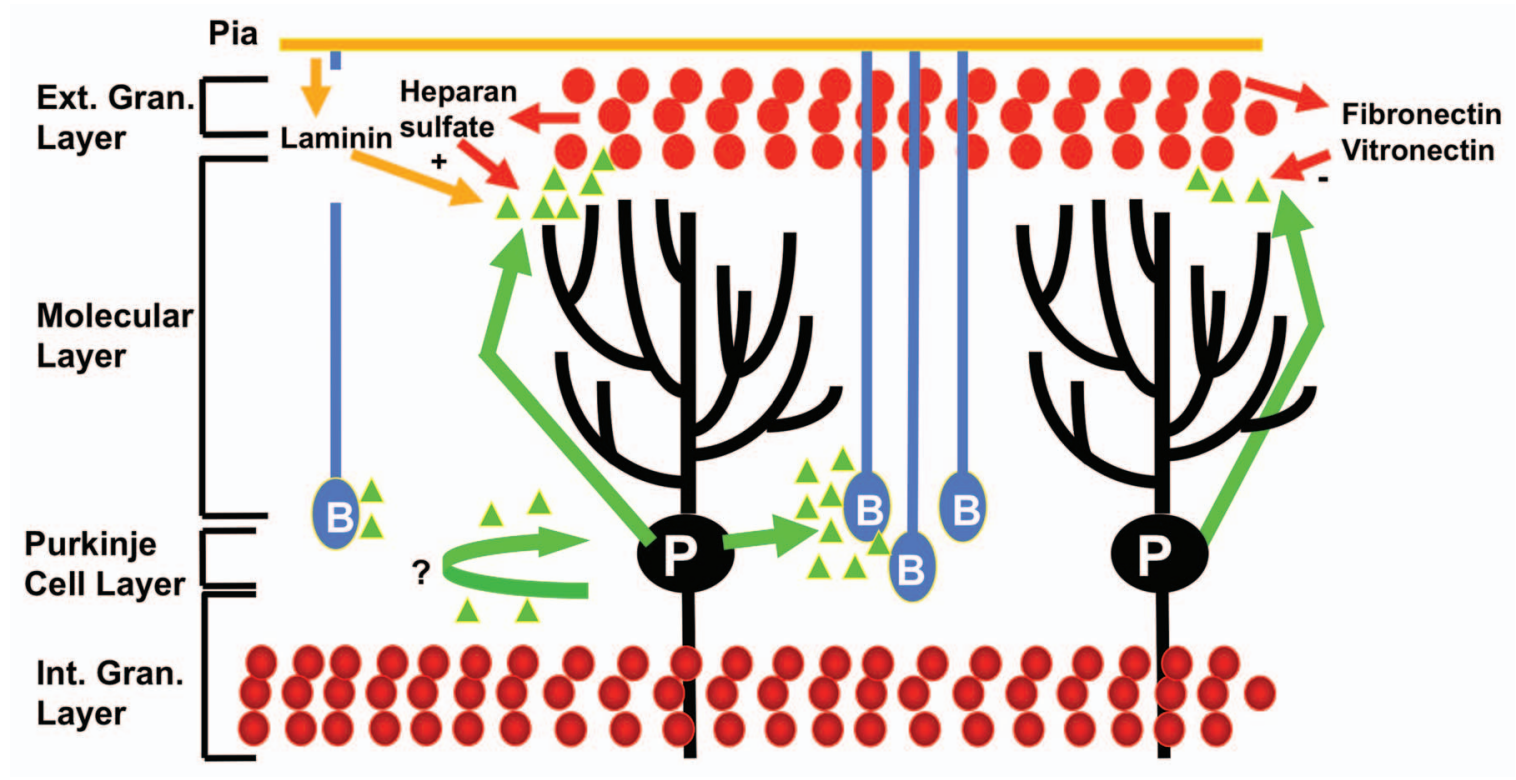

FIGURE 3 | Effects of sonic hedgehog (represented by green triangles) on cerebellar development. At the postnatal period, sonic hedgehog is secreted by the Purkinje neurons $(P)$, triggering mitosis in the outer external granular cell layer (cerebellar granular neuronal precursor cells illustrated by red circles), Bergmann glia (B) differentiation, and also possibly Purkinje cells maturation. The promitogenic effect on cerebellar granular neuronal precursor cells is synergized by cooperative modulators such as laminin and heparin sulfate, whereas fibronectin and fibronectin act as negative modulators. Mature granular cells are represented at the level of the internal granular layer (bottom part of the figure). Adapted from Vaillant and Monard (2009). week (Landis and Mullen, 1978; Sotelo and Alvarado-Mallart, 1986). This strain has undergone an extensive investigation (Wang and Morgan, 2007). Several independent phenotypic alleles have been identified with mutations in the Nnal gene. The model is characterized by a moderate ataxia developing between three and four weeks of age. The degeneration of Purkinje neurons begins around 18 days and progresses quickly over two weeks. At about four months, most of the Purkinje neurons have degenerated. Before Purkinje cells start degenerating, they appear to receive all their synaptic contacts (Landis and Mullen, 1978). The mice show impaired eyeblink conditioning and abnormal spatial navigation learning.

\section{MUTATIONS OF HERC GENE}

Proteins with HECT domains act as ubiquitin ligases. Recently, it has been shown that mutations in the highly conserved $\mathrm{N}$ terminal RCC1-like domain of the HERC1 protein cause a progressive Purkinje cell loss leading to severe ataxia with reduced growth and lifespan in homozygous mice aged over two months (tambaleante mutant mice; Mashimo et al., 2009). Activities of the proteins encoded by the HERC gene family are critical in a number of important cellular processes such as cell cycle, cell signaling, and membrane trafficking. It is now established that they play a key contribution in the physiology of Purkinje neurons.

\section{REMODELING OF THE OLIVOCEREBELLAR PROJECTION AND COMPENSATION FOLLOWING AN INJURY TO THE CEREBELLUM}

The olivocerebellar tract plays a major role in the control and regulation of the striated muscle system, although non-exclusively.
Several authors have pointed out its contribution in motor learning (Apps and Lee, 2002). After leaving the inferior olive nucleus, the olivocerebellar axon crosses the midline between the bilateral olives and enters the cerebellum via the contralateral inferior cerebellar peduncle. The axon ramifies into thick branches and thin collaterals. Climbing fibers are characterized by strong synaptic connections to Purkinje cells with an exclusive one-to-one relationship (Eccles et al., 1966; Sugihara, 2006). There is an average of 6.6 climbing fibers per axon in adult rats (Sugihara et al., 2001). Climbing fibers originating from one axon send thin collaterals to cerebellar nuclei and the granular layer, and end in a narrow longitudinal band called microzone (Sugihara et al., 1999). During normal development, the olivocerebellar axon undergoes a remodeling to reach the final configuration (Sugihara, 2006). Studies in newborn rats at postnatal days 4-7 (P4-P7) have shown that there are many more nuclear collaterals and swellings as compared to adult olivocerebellar axons, with swellings more densely packed (Sugihara, 2006). The basic organization of the olivocerebellar tract is reached at P4-P7, since the paths and destinations of the collaterals (cerebellar nuclei and the granular layer) are nearly identical with the adult configuration. The microzonal distribution is already present, suggesting that the pattern of projection is determined by a molecular recognition mechanism that is active from the beginning of the formation of the olivocerebellar projection. (Sugihara, 2005, 2006). Nevertheless, immature-so-called "nest" - climbing fibers can be distinguished from adult climbing fibers by their morphological aspect. As pointed by Sugihara, nest-type climbing fibers are characterized by a dense aggregation of swellings around the soma of a Purkinje cell with a few long fibers extending outside the aggregation. At the nest stage, 
Purkinje cell shows a single apical dendrite beginning to grow while other short protrusions in the soma vanish. The terminal arbor of the climbing fiber moves upwards to cover the stem of the apical dendrite ('capuchon' or 'hood') and to cover the dendritic tree proximally (mature climbing fiber) over the next 10 days (Mason et al., 1990). Before the nest period, the terminal portion of olivocerebellar axons (still called 'climbing fibers') creeps between Purkinje cells aligned in the multiple-cellular layer. They are designated as "creeper" (Chedotal and Sotelo, 1993). The "transitional type" has a terminal arbor with features intermediate between those of the nest and the creeper types (Sugihara, 2005). Transitional-type terminal arbors are characterized by thin terminal fibers with moderate aggregations of swellings around Purkinje cells. Other types include the "atrophic nest," with less swellings and smaller harbors as compared to the full nest. It is assumed that the remodeling of climbing fibers is mainly due to local factors in the cerebellar cortex, rather than an intrinsic programming (Sugihara, 2006). Because both the granular layer and the nest-type climbing fibers emerge early in the vermis, it has been suggested that the granule cells and their parallel fibers might subserve the remodeling of nascent climbing fibers.

Another major event is the decrease in the number of climbing fibers (Crépel et al., 1976). The elimination of supernumerary climbing fibers will reduce the ratios climbing fibers/single axons from 100 (creeper stage) at P5 up to about seven for the adult stage, indicating an important retraction or pruning phenomenon (Sugihara, 2006). Glia likely controls this mechanism (Awasaki and Ito, 2004). The change from a multiple innervation of Purkinje cells by climbing fibers to a monoinnervation is observed during the first two and three postnatal weeks in rodents (Scelfo and Strata, 2005). A competition occurs between multiple climbing fibers at the level of the soma and the proximal dendrite of the Purkinje neuron, with elimination of climbing fibers except one (Hashimoto and Kano, 2003). There is a general agreement that climbing fiber remodeling from the creeper to the nest type is a major event for the synaptic maturation and the initial selection process (Sugihara, 2006).

Interestingly, targeted deletion of mGluR1 gene causes both developmental defects and dysfunction of the cerebellum. mGluR1-/- mice exhibit abnormal regression of multiple climbing fiber innervation, impaired long-term depression, and abnormal motor coordination (Ichise et al., 2000). This illustrates that a receptor is involved both in developmental processes and synaptic plasticity, providing a bridge between these neurobiological processes.

The changes in the olivocerebellar system reported above are fundamental events linking development and learning. They are a prerequisite to reach functional olivocerebellar units. Cerebella which have been degranulated by post-natal X-ray exposure show a multiple innervation of Purkinje neurons by climbing fibers which is maintained (Mariani et al., 1990).

Following unilateral transection of climbing fibers early in development, the contralateral inferior olive degenerates. New axons emerging from the unaffected inferior olive reach the denervated hemicerebellum to partly recreate the olivocerebellar circuit (Sugihara et al., 2003). This reinnervation is associated with an improvement in motor abilities (Dixon et al., 2005). It has been shown that the amount of transcommissural reinnervation is directly correlated with spatial performance (Willson et al., 2007). Partial circuit repair confers a significant benefit from the functional point of view. The neonatal period might be particularly suited for procedures aiming to assist, promote, or guide reinnervation.

Innervation of multiple climbing fibers onto Purkinje cells may persist in adulthood in protein kinase C-gamma mutant mice (Chen et al., 1995). These mutant mice exhibit an impaired motor coordination but both eyeblink conditioning and cerebellar long-term depression are preserved. This latter phenomenon had been considered as a prerequisite for cerebellar motor learning, but recent studies show no motor learning impairment in mutant mice lacking parallel fiber-Purkinje neuron synapses long-term depression, demonstrating that this is not an essential step for cerebellar motor learning (Schonewille et al., 2011).

Compensatory mechanisms occur also for genetically determined mutant mice such as Lurcher, which represents a natural model of olivocerebellar degeneration (Cendelín et al., 2009). They carry a mutation of the glutamate receptor delta2-subunit gene which is predominantly expressed by Purkinje neurons (Zuo et al., 1997). Homozygous mutants are not viable. A complete postnatal loss of Purkinje cells and a secondary decrease in the number of granule cells/inferior olive neurons occurs. Granule cells and neurons of the inferior olive degenerate due to the loss of Purkinje neurons (Wetts and Herrup, 1982). The lack of proliferation of granule cells precursors is primarily due to the deficit in the mitogenic effects of sonic hedgehog (Sajan et al., 2010). The degeneration of Purkinje neurons is complete at P90. Young adult heterozygous Lurcher mice constitute an excellent model to investigate the role of the cerebellar cortex in motor performance-including the acquisition of new motor abilitiesdue to the early postnatal degeneration of nearly all Purkinje and granular cells. They show compensatory adjustments in the correlations of firings between cerebellar nuclei and brainstem nuclei such as red nuclei (Porras-García et al., 2010).

\section{NEURODEVELOPMENTAL DISORDERS}

Thanks to novel perinatal neuroimaging techniques, cerebellar malformations are increasingly recognized in the fetal period (Bolduc et al., 2011). A typical example is Joubert syndrome. The disorder presents with developmental delay, hypotonia, impaired respiration, abnormal eye movements, and ataxia (Joubert et al., 1969). Motor learning is strongly impaired. The "Molar tooth sign" (deep interpeduncular fossa, enlarged superior cerebellar peduncles which are more horizontally oriented and hypoplastic cerebellar vermis) is very suggestive. Joubert syndrome is associated with mutations of genes encoding components of the primary cilia. Interestingly, primary cilia are determinant for sonic hedgehog signal transduction (Vaillant and Monard, 2009). Disruption of primary cilia formation blocks the proliferation of neural progenitors of granule cells mediated by sonic hedgehog (Spassky et al., 2008).

Another disorder clearly associated with learning disabilities is rhombencephalosynapsis, a malformation of the hindbrain characterized by fusion of the cerebellar hemispheres and dentate nuclei. It is assumed that the disorder is due to a failure of dorsal 
patterning at the midbrain-hindbrain boundary (Pasquier et al., 2009). Other cerebellar malformations which are encountered in daily practice include Dandy-Walker malformation, vermis hypoplasia, mega cisterna magna, and posterior fossa retrocerebellar cyst. Sonic hedgehog might also be involved in the pathogenesis of Dandy-Walker malformation through a contribution of Zinc finger transcription factors which modulate the sonic hedgehog pathway (Aruga, 2004).

Autism spectrum disorders are characterized by difficulties in communication, social skills, and repetitive behavior. Cerebellar networks might be critically involved in the pathogenesis of autism. An immune dysfunction with local inflammation contributes to the pathogenesis of autism (Wei et al., 2011). The expression of IL-6 is increased in the cerebellum of autistic patients. IL-6 impacts upon the development of the cerebellum, impairing neural cell adhesion, migration, and causing an excessive formation of excitatory synapses (Wei et al., 2011).

Recent studies underline the a high prevalence of neurologic, developmental, and functional disabilities including motor, cognitive, language, and social-behavioral deficits in children with cerebellar malformations (Bolduc et al., 2011). The associated supratentorial anomalies, chromosomal findings, and malformations affecting the cerebellar vermis are independent predictors of neurodevelopmental disabilities. Furthermore, the associated supratentorial anomalies and chromosomal findings are predictive of cognitive impairment, gross and fine motor delay. Moreover, malformations of the vermis are predictors of gross motor delays (Bolduc et al., 2011). There is a clear need for early intervention services aiming to improve the daily care of these patients, especially when gross motor impairments and learning deficits are on the forefront of the syndrome.

\section{IMPACT OF VERY PREMATURE BIRTH UPON CEREBELLAR DEVELOPMENT}

Very premature birth (less than 32 weeks of gestation) may impact upon the cerebellar development, with consequences upon cognition and behavior. The prevalence of preterm birth is estimated to 5-9\% (Spreen et al., 1995). The prevalence of very preterm birth is about $0.9 \%$. Several disabilities have a higher incidence in preterms, such as developmental delay, learning deficits, cerebral palsy, and sensory impairments. The most preterm infants often show the most severe disabilities. Neonates following a gestation of less than 32 weeks are developmentally immature and their brain is particularly susceptible. Several types of brain injury have been reported, such as periventricular hemorrhage and hemorrhagic infarction, periventricular leukomalacia, and diffuse white matter injury. The injury of the white matter is now detected in the majority of very premature neonates (Dyet et al., 2006). These findings may occur in the cerebellum as well, and are often associated with a development delay of the posterior fossa structures, often reduced in size (Figure 4). There is a correlation between the MRI findings and the psychomotor outcome (Drobyshevsky et al., 2007). Although Purkinje neurons and neurons of the cerebellar nuclei develop early in utero, the granule cells show developmental/migrational processes occurring during the last trimester. Therefore, a hemorrhage in the cerebellum will impair these processes. Indeed, premature neonates are at risk for cerebellar hemorrhage. The hemorrhage may be unilateral and associated with extra-cerebellar lesions (Limperopoulos et al., 2005). Neonates with a cerebellar hemorrhage show a slower cerebellar growth. The mortality is higher in this case. It is estimated that the maximal cerebellar vulnerability is between 26 and 28 weeks (Limperopoulos et al., 2005). Cerebellar development may also be affected by extra-cerebellar lesions, as a result of loss of trophic actions exerted by pathways projecting to the cerebellum. Contralateral cerebellar atrophy can also occur as the result of a supratentorial lesion.

The likelihood to present sensori-motor combined with cognitive disabilities is higher in case of very premature birth. It has been shown that there is higher risk to develop psychiatric/behavioral disorders later in life (Byrne et al., 2007). Premature children are at higher risk to develop autism or autism spectrum disorders (Limperopoulos et al., 2008). There is growing evidence that the cerebellum plays key-roles in the pathogenesis of autism, as pointed out earlier. Individuals born very preterm tend to have lower IQs as compared to matched controls and often show trends toward academic difficulties in adolescence and young adulthood (Allin et al., 2008; Narberhaus et al., 2009). Volumetric studies performed in adolescents with a history of very preterm birth have shown reduced cerebellar size, especially in the lateral lobes which are known to participate in cognitive operations (Allin et al., 2005). Regional gray matter volumes are reduced in sensorimotor and parieto-occipital regions.

The recent fMRI study of visuo-perceptual learning processing in adults born very preterm has shown an increased BOLD signal response as compared to controls during the recognition phase in the right cerebellum and in the anterior cingulate gyri (Narberhaus et al., 2009). However, this disappeared after controlling for the probability of the absolute amount of gray matter in the hippocampus. The authors have hypothesized that cerebellar atrophy associated with hippocampal atrophy, affect cerebellar activation only when hippocampal size is not accounted for. It seems that very preterm individuals have a less efficient neural processing.

It is currently unclear how very preterm birth impacts upon epigenetic factors. Still, this is a question of great interest. Certain molecules, like BDNF, play major roles in cerebellar development and are involved in the recovery from hypoxia in the neonatal period (Almli et al., 2000).

\section{THE EXAMPLE OF A COMMON DEVELOPMENTAL DISORDER: DEVELOPMENTAL DYSLEXIA}

Developmental dyslexia can be defined as "a disorder in children who, despite conventional classroom experience, fail to attain the language skills of reading, writing, and spelling commensurate with their intellectual abilities" (according to the World Federation of Neurology). Its prevalence is very high, from $3 \%$ to $10 \%$ of learning disabilities (Bishop and Snowling, 2004). Skills in children are very heterogeneous. There is evidence that dyslexia is associated with mild clumsiness and deficit in fine motor skills (Nicolson and Fawcett, 2011). Dyslexia is associated with difficulties in making skills automatic (Nicolson and Fawcett, 1990). Most patients exhibit balance difficulties. 

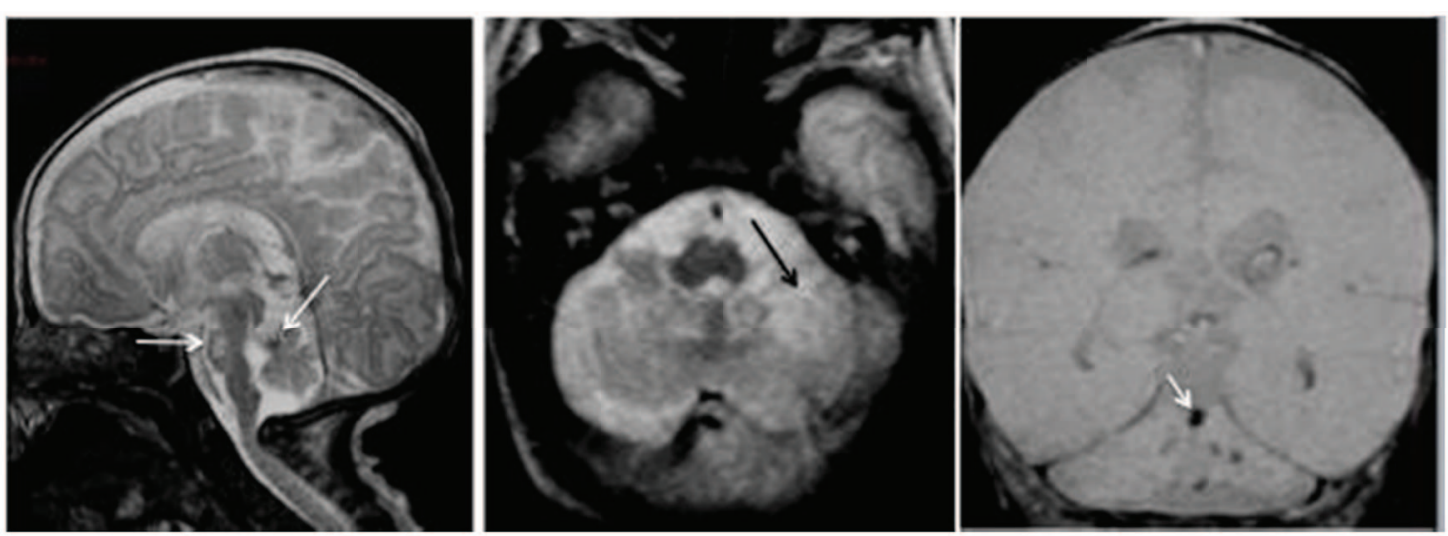

FIGURE 4 | Premature baby born at 27 gestational weeks and MRI performed at $\mathbf{3 9}$ gestational weeks. Left panel: the sagittal T2-weighted image shows reduced size of the posterior fossa (vertical tentorium), small vermis, and pons with a hemorrhagic dark spot on the anterior vermis (left arrow) and bright signal in the pons (right arrow) corresponding to hypoxic ischemic necrosis. Middle panel: the axial T2-WI shows the ischemic necrosis of the left cerebellar hemisphere (arrow) appearing bright. Right panel: the coronal T2 gradient-echo image shows multifocal dark signals in the vermis (arrow) and the left cerebellar hemisphere corresponding to hemorrhagic foci.
The hypothesis of a cerebellar dysfunction is straightforward given the major role played by the cerebellum in learning, automaticity of skills and its contribution to language (Nicolson et al., 1995). An ontogenetic framework has been proposed to explain how cerebellar differences at birth cause a range of difficulties in children (Nicolson and Fawcett, 2011). The language-related regions of the cerebellum, namely lobules VI and VIIB, would be affected in dyslexia. Procedural learning circuits involving the cerebellum would be primarily affected. An abnormal development of the brain, including the cerebellum, during the gestation has been proposed. Genetic investigations will very likely lead to the discovery of the mechanisms leading to some of these learning disabilities.

\section{CONCLUSION}

In this mini-review, we have summarized recent advances in our understanding of the molecular mechanism governing cerebellar development. We have discussed the complex interactions

\section{REFERENCES}

Allin, M. P. G., Salaria, S., Nosarti, C., Wyatt, J., Rifkin, L., and Murray, R. M. (2005). Vermis and lateral lobes of the cerebellum in adolescents born very preterm. Neuroreport 16, 1821-1824.

Allin, M. P. G., Walshe, M., Fern, A., Nosarti, C., Rushe, T., Cuddy, M., Wyatt, J., Rifkin, L., and Murray, R. (2008). Cognitive maturation in preterm and term born adolescents. J. Neurol. Neurosurg. Psychiatry 79, 381-386.

Almli, C. R., Levy, T. J., Han, B. H., Shah, A. R., Gidday, J. M., and Holtzman, D. M. (2000). BDNF protects against spatial memory deficits following neonatal hypoxia-ischemia. Exp. Neurol. 166, 99-114.
Apps, R., and Lee, S. (2002). Central regulation of cerebellar climbing fibre input during motor learning. J. Physiol. 541, 301-317.

Aruga, J. (2004). The role of Zic genes in neural development. Mol. Cell. Neurosci. 26, 205-221.

Awasaki, T., and Ito, K. (2004). Engulfing action of glial cells is required for programmed axon pruning during Drosophila metamorphosis. Curr. Biol. 14, 668-677.

Beffert, U., Weeber, E. J., Morfini, G., Ko, J., Brady, S. T., Tsai, L. H., Sweatt, J. D., and Herz, J. (2004). Reelin and cyclin-dependent kinase 5 -dependent signals cooperate in regulating neuronal migration and synaptic transmission. J. Neurosci. 24, 1897-1906.

between cerebellar development and motor learning. The identification of several pathways which are potential targets for novel therapies in the future, such as cerebellar neurosteroidogenesis, En1/2, Math1, Ptfla, Rora, or sonic hedgehog, is now bringing hope in a field which has often remained neglected because of a lack of understanding of the molecular events leading to the malformations. There is still a growing need to identify new targets, since neurodevelopmental disorders are heterogeneous and will impact upon the whole life of patients in most cases. Protecting the developing cerebellum - a concept which could be called cerebelloprotection-is now attracting the interest of the scientific community, especially with discoveries of the roles of the cerebellum in cognitive skills. Very preterm neonates are an example of a population of patients at risk and which could benefit from neuroprotecting actions.

\section{ACKNOWLEDGMENTS}

Mario Manto is supported by the FNRS-Belgium.

Bermingham, N. A., Hassan, B. A. Wang, V. Y., Fernandez, M., Banfi, S., Bellen, H. J., Fritzsch, B., and Zoghbi, H. Y. (2001). Proprioceptor pathway development is dependent on Math1. Neuron 30, 411-422.

Bishop, D. V., and Snowling, M. J. (2004). Developmental dyslexia and specific language impairment: same or different? Psychol. Bull. 130, 858-886.

Bolduc, M. E., du Plessis, A. J., Sullivan, N., Guizard, N., Zhang, X., Robertson, R. L., and Limperopoulos, C. (2011). Regional cerebellar volumes predict functional outcome in children with cerebellar malformations. Cerebellum.

Boukhtouche, F., Vodjdani, G., Jarvis, C. I., Bakouche, J., Staels, B., Mallet,
J., Mariani, J., Lemaigre-Dubreuil, Y., and Brugg, B. (2006). Human retinoic acid receptor-related orphan receptor alphal overexpression protects neurones against oxidative stress-induced apoptosis. J. Neurochem. 96, 1778-1789.

Byrne, M., Agerbo, E., Bennedsen, B., Eaton, W. W., and Mortensen, P. B. (2007). Obstetric conditions and risk of first admission with schizophrenia: a Danish national register based study. Schizophr. Res. 97, 51-59.

Carletti, B., and Rossi, F. (2008). Neurogenesis in the cerebellum. Neuroscientist 14, 91-100.

Cendelín, J., Korelusová, I., and Vozeh, F. (2009). The effect of cerebellar transplantation and enforced physical activity on motor skills and 
spatial learning in adult Lurcher mutant mice. Cerebellum 8, 35-45.

Chedotal, A., and Sotelo, C. (1993). The 'creeper stage' in cerebellar climbing fiber synaptogenesis precedes the 'pericellular nest' ultrastructural evidence with parvalbumin immunocytochemistry. Brain Res. Dev. Brain Res. 76, 207-220.

Cheh, M. A., Millonig, J. H., Roselli, L. M., Ming, X., Jacobsen, E., Kamdar, S., and Wagner, G. C. (2006). En2 knockout mice display neurobehavioral and neurochemical alterations relevant to autism spectrum disorder. Brain Res. 1116, 166-176.

Chen, C., Kano, M., Abeliovich, A., Chen, L., Bao, S., Kim, J. J., Hashimoto, K., Thompson, R. F., and Tonegawa, S. (1995). Impaired motor coordination correlates with persistent multiple climbing fiber innervation in PKC gamma mutant mice. Cell 83, 1233-1242.

Corrales, J. D., Blaess, S., Mahoney, E. M., and Joyner, A. L. (2006). The level of sonic hedgehog signaling regulates the complexity of cerebellar foliation. Development 133, 1811-1821.

Corrales, J. D., Rocco, G. L., Blaess, S., Guo, Q., and Joyner, A. L. (2004). Spatial pattern of sonic hedgehog signaling through Gli genes during cerebellum development. Development 131, 5581-5590.

Crépel, F., Mariani, J., and DelhayeBouchaud, N. (1976). Evidence for a multiple innervation of Purkinje cells by climbing fibers in the immature rat cerebellum. J. Neurobiol. 7, 567-578.

DeCamp, D. L., Thompson, T. M., de Sauvage, F. J., and Lerner, M. R. (2000). Smoothened activates Galphai-mediated signaling in frog melanophores. J. Biol. Chem. 275, 26322-26327.

Dehart, D. B., Lanoue, L., Tint, G. S., and Sulik, K. K. (1997). Pathogenesis of malformations in a rodent model for Smith-LemliOpitz syndrome. Am. J. Med. Genet. 68, 328-337.

Delerive, P., Monté, D., Dubois, G., Trottein, F., Fruchart-Najib, J., Mariani, J., Fruchart, J. C., and Staels, B. (2001). The orphan nuclear receptor ROR alpha is a negative regulator of the inflammatory response. EMBO Rep. 2, 42-48.

Delgado-García, J. M., and Gruart, A. (2002). The role of interpositus nucleus in eyelid conditioned responses. Cerebellum 1, 289-308.

Dixon, K. J., Hilber, W., Speare, S., Willson, M. L., Bower, A. J., and Sherrard, R. M. (2005). Post-lesion transcommissural olivocerebellar reinnervation improves motor function following unilateral pedunculotomy in the neonatal rat. Exp. Neurol. 196, 254-265.

Drobyshevsky, A., Bregman, J., Storey, P., Meyer, J., Prasad, P. V., Derrick, M., MacKendrick, W., and Tan, S. (2007). Serial diffusion tensor imaging detects white matter changes that correlate with motor outcome in premature infants. Dev. Neurosci. 29, 289-301.

Dyet, L. E., Kennea, N., Counsell, S. J., Maalouf, E. F., Ajayi-Obe, M., Duggan, P. J., Harrison, M., Allsop, J. M., Hajnal, J., Herlihy, A. H., Edwards, B., Laroche, S., Cowan, F. M., Rutherford, M. A. and Edwards, A. D. (2006). Natural history of brain lesions in extremely preterm infants studied with serial magnetic resonance imaging from birth and neurodevelopmental assessment. Pediatrics 118, 536-548.

Eccles, J. C., Llinás, R., and Sasaki, K. (1966). The excitatory synaptic action of climbing fibers on the Purkinje cells of the cerebellum. J. Physiol. 182, 268-296.

Ferretti, E., De Smaele, E., Miele, E., Laneve, P., Po, A., Pelloni, M., Paganelli, A., Di Marcotullio, L., Caffarelli, E., Screpanti, I., Bozzoni, I., and Gulino, A. (2008). Concerted microRNA control of Hedgehog signalling in cerebellar neuronal progenitor and tumour cells. EMBO J. 27, 2616-2627.

Fogarty, M. P., Emmenegger, B. A., Grasfeder, L. L., Oliver, T. G., and Wechsler-Reya, R. J. (2007). Fibroblast growth factor blocks Sonic hedgehog signaling in neuronal precursors and tumor cells. Proc. Natl. Acad. Sci. U.S.A. 104, 2973-2978.

Grimaldi, P., Parras, C., Guillemot, F., Rossi, F., and Wassef, M. (2009). Origins and control of the differentiation of inhibitory interneurons and glia in the cerebellum. Dev. Biol. $328,422-433$.

Hajós, F., Patel, A. J., and Balázs, R. (1973). Effect of thyroid deficiency on the synaptic organization of the rat cerebellar cortex. Brain Res. 50, 387-401.

Hamilton, B. A., Frankel, W. N., Kerrebrock, A. W., Hawkins, T. L., Fitzhugh, W., Kusumi, K., Russell, L. B., Mueller, K. L., van Berkel, V., Birren, B. W., Kruglyak, L., and Lander, E. S. (1996). Disruption of the nuclear hormone receptor ROR in staggerer mice. Nature 379, 736-739.

Harvey, J. A., Welsh, J. P., Yeo, C. H., and Romano, A. G. (1993).
Recoverable and nonrecoverable deficits in conditioned responses after cerebellar cortical lesions. $J$. Neurosci. 13, 1624-1635.

Hashimoto, K., and Kano, M. (2003). Functional differentiation of multiple climbing fiber inputs during synapse elimination in the developing cerebellum. Neuron 38 , 785-796.

Huard, J. M., Forster, C. C., Carter, M. L., Sicinski, P., and Ross, M. E. (1999). Cerebellar histogenesis is disturbed in mice lacking cyclin D2 Development 126, 1927-1935.

Hurtado de Mendoza, T., Perez-Garcia, C. G., Kroll, T. T., Hoong, N. H., O'Leary, D. D., and Verma, I. M. (2011). Antiapoptotic protein lifeguard is required for survival and maintenance of purkinje and granular cells. Proc. Natl. Acad. Sci. U.S.A. 108, 17189-17194.

Ichise, T., Kano, M., Hashimoto, K., Yanagihara, D., Nakao, K. Shigemoto, R., Katsuki, M., and Aiba, A. (2000). mGluR1 in cerebellar Purkinje cells essential for long-term depression, synapse elimination, and motor coordination. Science 288, 1832-1835.

Ito, M. (2006). Cerebellar circuitry as a neuronal machine. Prog. Neurobiol. $78,272-303$.

Jetten, A. M. (2009). Retinoid-related orphan receptors (RORs): critical roles in development, immunity, circadian rhythm, and cellular metabolism. Nucl. Recept. Signal. 7 , e003.

Joubert, M., Eisenring, J. J., Robb, J. P., and Andermann, F. (1969). Familial agenesis of the cerebellar vermis. A syndrome of episodic hyperpnea, abnormal eye movements, ataxia, and retardation. Neurology $19,813-825$.

Journiac, N., Jolly, S., Jarvis, C. Gautheron, V., Rogard, M. Trembleau, A., Blondeau, J. P., Mariani, J., and Vernet-der Garabedian, B. (2009). The nuclear receptor ROR(alpha) exerts a bi-directional regulation of IL-6 in resting and reactive astrocytes. Proc. Natl. Acad. Sci. U.S.A. 106, 21365-21370

Koibuchi, N. (2008). The role of thyroid hormone on cerebellar development. Cerebellum 7, 530-533.

Koibuchi, N., Jingu, H., Iwasaki, T., and Chin, W. W. (2003). Current perspectives on the role of thyroid hormone in growth and development of cerebellum. Cerebellum 2, 279-289.

Kuemerle, B., Zanjani, H., Joyner, A. and Herrup, K. (1997). Pattern deformities and cell loss in
Engrailed-2 mutant mice suggest two separate patterning events during cerebellar development. $J$. Neurosci. 17, 7881-7889.

Landis, D. M., and Sidman, R. L. (1978). Electron microscopic analysis of postnatal histogenesis in the cerebellar cortex of staggerer mutant mice. J. Comp. Neurol. 179, 831-863.

Landis, S. C., and Mullen, R. J. (1978). The development and degeneration of Purkinje cells in pcd mutant mice. J. Comp. Neurol. 177, 125-143. Lanoue, L., Dehart, D. B., Hinsdale, M. E., Maeda, N., Tint, G. S., and Sulik, K. K. (1997). Limb, genital, CNS, and facial malformations result from gene/environment-induced cholesterol deficiency: further evidence for a link to sonic hedgehog. Am. J. Med. Genet. 73, 24-31.

Leto, K., and Rossi, F. (2011). Specification and differentiation of cerebellar GABAergic neurons. Cerebellum.

Limperopoulos, C., Bassan, H., Sullivan, N. R., Soul, J. S., Robertson, R. L. Jr., Moore, M., Ringer, S. A., Volpe, J. J., and du Plessis, A. J. (2008). Positive screening for autism in ex-preterm infants: prevalence and risk factors. Pediatrics 121, 758-765.

Limperopoulos, C., Soul, J. S., Haidar, H., Huppi, P. S., Bassan, H., Warfield, S. K., Robertson, R. L., Moore, M., Akins, P., Volpe, J. J., and du Plessis, A. J. (2005). Impaired trophic interactions between the cerebellum and the cerebrum among preterm infants. Pediatrics 116, 844-850.

Manto, M. (2010). Cerebellar Disorders. A Practical Approach to Diagnosis and Management. Cambridge, UK: Cambridge University Press.

Mariani, J., Benoit, P., Hoang, M. D., Thomson, M. A., and DelhayeBouchaud, N. (1990). Extent of multiple innervation of cerebellar Purkinje cells by climbing fibers in adult $\mathrm{X}$-irradiated rats. Comparison of different schedules of irradiation during the first postnatal week. Brain Res. Dev. Brain Res. 57, 63-70.

Mashimo, T., Hadjebi, O., AmairPinedo, F., Tsurumi, T., Langa, F., Serikawa, T., Sotelo, C., Guénet, J. L., and Rosa, J. L. (2009). Progressive Purkinje cell degeneration in tambaleante mutant mice is a consequence of a missense mutation in HERC1 E3 ubiquitin ligase. PLoS Genet. 5, e1000784. doi: 10.1371/journal.pgen.1000784

Mason, C. A., Christakos, S., and Catalano, S. M. (1990). Early climbing fiber interactions with Purkinje 
cells in the postnatal mouse cerebellum. J. Comp. Neurol. 297, 77-90.

Narberhaus, A., Lawrence, E., Allin, M. P. G., Walshe, M., McGuire, P. K., Rifkin, L., Murray, R. M., and Nosarti, C. (2009). Neural substrates of visual paired associates in young adults with a history of very preterm birth: alterations in fronto-parieto-occipital networks and caudate nucleus. Neuroimage 47, 1884-1893.

Nicholson, J. L., and Altman, J. (1972). Synaptogenesis in the rat cerebellum: effects of early hypo- and hyperthyroidism. Science 176, 530-532.

Nicolson, R. I., and Fawcett, A. J. (1990). Automaticity: a new framework for dyslexia research? Cognition 35, 159-182.

Nicolson, R. I., and Fawcett, A. J. (2011). Dyslexia, dysgraphia, procedural learning and the cerebellum. Cortex 47, 117-127.

Nicolson, R. I., Fawcett, A. J., and Dean, P. (1995). Time estimation deficits in developmental dyslexia: evidence of cerebellar involvement. Proc. Biol. Sci. 259, 43-47.

Nicot, A., Lelievre, V., Tam, J., Waschek, J. A., and DiCicco-Bloom, E. (2002). Pituitary adenylate cyclaseactivating polypeptide and sonic hedgehog interact to control cerebellar granule precursor cell proliferation. J. Neurosci. 22, 9244-9254.

Pasquier, L., Marcorelles, P., Loget, P., Pelluard, F., Carles, D., Perez, M. J., Bendavid, C., de La Rochebrochard, C., Ferry, M., David, V., Odent, S., and Laquerrière, A. (2009). Rhombencephalosynapsis and related anomalies: a neuropathological study of 40 fetal cases. Acta. Neuropathol. 117, 185-200.

Porras-García, E., SánchezCampusano, R., Martínez-Vargas, D., Domínguez-del-Toro, E., Cendelín, J., Vozeh, F., and DelgadoGarcía, J. M. (2010). Behavioral characteristics, associative learning capabilities, and dynamic association mapping in an animal model of cerebellar degeneration. $J$. Neurophysiol. 104, 346-365.

Pujadas, L., Gruart, A., Bosch, C., Delgado, L., Teixeira, C. M., Rossi, D., de Lecea, L., Martínez, A., Delgado-García, J. M., and Soriano, E. (2010). Reelin regulates postnatal neurogenesis and enhances spine hypertrophy and long-term potentiation. J. Neurosci. 30, 4636-4649.

Raoul, C., Pettmann, B., and Henderson, C. E. (2000). Active killing of neurons during development and following stress: a role for p75(NTR) and Fas? Curr. Opin. Neurobiol. 10, 111-117.

Rubin, J. B., Choi, Y., and Segal, R. A. (2002). Cerebellar proteoglycans regulate sonic hedgehog responses during development. Development 129, 2223-2232.

Sajan, S. A., Waimey, K. E., and Millen, K. J. (2010). Novel approaches to studying the genetic basis of cerebellar development. Cerebellum 9, 272-283.

Sakamoto, H., Ukena, K., and Tsutsui, K. (2001). Effects of progesterone synthesized de novo in the developing Purkinje cell on its dendritic growth and synaptogenesis. $J$. Neurosci. 21, 6221-6232.

Sasahara, K., Shikimi, H., Haraguchi, S., Sakamoto, H., Honda, S., Harada, N., and Tsutsui, K. (2007). Mode of action and functional significance of estrogen-inducing dendritic growth, spinogenesis, and synaptogenesis in the developing Purkinje cell. J. Neurosci. 27, 7408-7417.

Scelfo, B., and Strata, P. (2005) Correlation between multiple climbing fiber regression and parallel fiber response development in the postnatal mouse cerebellum. Eur. J. Neurosci. 21, 971-978.

Schonewille, M., Gao, Z., Boele, H. J., Veloz, M. F., Amerika, W. E., Simek, A. A., De Jeu, M. T., Steinberg, J. P., Takamiya, K., Hoebeek, F. E., Linden, D. J., Huganir, R. L., and De Zeeuw, C. I. (2011). Reevaluating the role of LTD in cerebellar motor learning. Neuron 70 43-50.

Sellick, G. S., Barker, K. T., StolteDijkstra, I., Fleischmann, C., Coleman, R. J., Garrett, C., Gloyn, A. L., Edghill, E. L., Hattersley, A. T., Wellauer, P. K., Goodwin, G., and Houlston, R. S. (2004). Mutations in PTF1A cause pancreatic and cerebellar agenesis. Nat. Genet. 36, 1301-1305.

Sillitoe, R. V., Vogel, M. W., and Joyner, A. L. (2010). Engrailed homeobox genes regulate establishment of the cerebellar afferent circuit map. $J$. Neurosci. 30, 10015-10024.

Sotelo, C., and Alvarado-Mallart, R. M. (1986). Growth and differentiation of cerebellar suspensions transplanted into the adult cerebellum of mice with heredodegenerative ataxia. Proc. Natl. Acad. Sci. U.S.A. 83, 1135-1139.

Spassky, N., Han, Y. G., Aguilar, A., Strehl, L., Besse, L., Laclef, C., Ros, M. R., Garcia-Verdugo, J. M., and Alvarez-Buylla, A. (2008). Primary cilia are required for cerebellar development and Shh-dependent expansion of progenitor pool. Dev. Biol. 317, 246-259.

Spreen, O., Risser, A. H., and Edgell, D. (1995). Prematurity and Low Birth Weight. Developmental Neuropsychology. Oxford, UK: Oxford University Press.

Sudarov, A., Turnbull, R. K., Kim, E. J., Lebel-Potter, M., Guillemot, F., and Joyner, A. L. (2011). Ascll genetics reveals insights into cerebellum local circuit assembly. J. Neurosci. $31,11055-11069$

Sugihara, I. (2005). Microzonal projection and climbing fiber remodelling in single olivocerebellar axons of newborn rats at postnatal days 4-7. J. Comp. Neurol. 487, 93-106.

Sugihara, I. (2006). Organization and remodeling of the olivocerebellar climbing fiber projection. Cerebellum 5, 15-22.

Sugihara, I., Lohof, A. M., Letellier, M., Mariani, J., and Sherrard, R. M. (2003). Post-lesion transcommissural growth of olivary climbing fibres creates functional synaptic microzones. Eur. J. Neurosci. 18 3027-3036.

Sugihara, I., Wu, H-S., and Shinoda, Y. (1999). Morphology of single olivocerebellar axons labeled with biotinylated dextran amine in the rat. J. Comp. Neurol. 414 131-148.

Sugihara, I., Wu, H-S., and Shinoda, Y. (2001). The entire trajectories of single olivocerebellar axons in the cerebellar cortex and their contribution to cerebellar compartmentalization. J. Neurosci. 21, 7715-7723.

Tsutsui, K. (2008). Progesterone biosynthesis and action in the developing neuron (review). Endocrinology 149, 2757-2761.

Vaillant, C., Didier-Bazes, M., Hutter, A., Belin, M. F., and Thomasset, N. (1999). Spatiotemporal expression patterns of metalloproteinases and their inhibitors in the postnatal developing rat cerebellum. $J$. Neurosci. 19, 4994-5004.

Vaillant, C., and Monard, D. (2009). SHH pathway and cerebellar development. Cerebellum 8, 291-301.

Wang, T., and Morgan, J. I. (2007). The Purkinje cell degeneration (pcd) mouse: an unexpected molecular link between neuronal degeneration and regeneration. Brain Res. 1140 26-40.

Wechsler-Reya, R. J., and Scott, M. P. (1999). Control of neuronal precursor proliferation in the cerebellum by Sonic Hedgehog. Neuron 22, 103-114.

Wei, H., Zou, H., Sheikh, A. M., Malik, M., Dobkin, C., Brown, W. T., and
Li, X. (2011). IL-6 is increased in the cerebellum of autistic brain and alters neural cell adhesion migration and synaptic formation. J. Neuroinflammation 8,52 .

Weiner, H. L., Bakst, R., Hurlbert, M. S., Ruggiero, J., Ahn, E., Lee, W. S., Stephen, D., Zagzag, D., Joyner, A. L., and Turnbull, D. H. (2002). Induction of medulloblastomas in mice by sonic hedgehog, independent of Gli1. Cancer Res. 62, 6385-6389.

Wetts, R., and Herrup, K. (1982). Interaction of granule, Purkinje and inferior olivary neurons in lurcher chimeric mice. II. Granule cell death. Brain Res. 250, 358-362.

Willson, M. L., Bower, A. J., and Sherrard, R. M. (2007). Developmental neural plasticity and its cognitive benefits: olivocerebellar reinnervation compensates for spatial function in the cerebellum. Eur. J. Neurosci. 25, 1475-1483.

Yamada, M., Terao, M., Terashima, T., Fujiyama, T., Kawaguchi, Y., Nabeshima, Y., and Hoshino, M. (2007). Origin of climbing fiber neurons and their developmental dependence on Ptfla. J. Neurosci. 27, 10924-10934.

Zou, Y. R., Kottmann, A. H., Kuroda, M., Taniuchi, I., and Littman, D. R. (1998). Function of the chemokine receptor CXCR4 in haematopoiesis and in cerebellar development. Nature 393, 595-599.

Zuo, J., De Jager, P. L., Takahashi, K. A., Jiang, W., Linden, D. J., and Heintz, N. (1997). Neurodegeneration in Lurcher mice caused by mutation in delta2 glutamate receptor gene. Nature 388, 769-773.

Conflict of Interest Statement: The authors declare that the research was conducted in the absence of any commercial or financial relationships that could be construed as a potential conflict of interest.

Received: 01 December 2011; accepted: 04 January 2012; published online: 23 January 2012.

Citation: Manto $M U$ and Jissendi $P$ (2012) Cerebellum: links between development, developmental disorders and motor learning. Front. Neuroanat. 6:1. doi: 10.3389/fnana.2012.00001

Copyright (c) 2012 Manto and Jissendi. This is an open-access article distributed under the terms of the Creative Commons Attribution Non Commercial License, which permits non-commercial use, distribution, and reproduction in other forums, provided the original authors and source are credited. 